\title{
Design methodology for bio-based processing: Biodiesel and fatty alcohol production
}

\author{
Simasatikul, Lida; Arpornwichanopa, Amornchai; Gani, Rafiqul
}

Published in:

Computers \& Chemical Engineering

Link to article, DOI:

10.1016/j.compchemeng.2013.01.018

Publication date:

2013

Link back to DTU Orbit

Citation (APA):

Simasatikul, L., Arpornwichanopa, A., \& Gani, R. (2013). Design methodology for bio-based processing:

Biodiesel and fatty alcohol production. Computers \& Chemical Engineering, 57, 48-62.

https://doi.org/10.1016/j.compchemeng.2013.01.018

\section{General rights}

Copyright and moral rights for the publications made accessible in the public portal are retained by the authors and/or other copyright owners and it is a condition of accessing publications that users recognise and abide by the legal requirements associated with these rights.

- Users may download and print one copy of any publication from the public portal for the purpose of private study or research.

- You may not further distribute the material or use it for any profit-making activity or commercial gain

- You may freely distribute the URL identifying the publication in the public portal

If you believe that this document breaches copyright please contact us providing details, and we will remove access to the work immediately and investigate your claim 


\title{
Design methodology for bio-based processing: Biodiesel and fatty alcohol production
}

\author{
Lida Simasatitkul a ${ }^{a}$ Amornchai Arpornwichanop ${ }^{\mathrm{a}, *}$, Rafiqul Gani ${ }^{\mathrm{b}}$ \\ a Department of Chemical Engineering, Faculty of Engineering, Chulalongkorn University, Bangkok 10330, Thailand \\ ${ }^{\mathrm{b}}$ Department of Chemical \& Biochemical Engineering, Technical University of Denmark, Soltofts Plads, Building 229, DK-2800 Lyngby, Denmark
}

\section{A R T I C L E I N F O}

\section{Article history:}

Received 17 September 2012

Received in revised form 13 January 2013

Accepted 30 January 2013

Available online $\mathrm{xxx}$

\section{Keywords:}

Design methodology

Superstructure

Process intensification

Biodiesel production

Fatty alcohol production

\begin{abstract}
A B S T R A C T
A systematic design methodology is developed for producing multiple main products plus side products starting with one or more bio-based renewable source. A superstructure that includes all possible reaction and separation operations is generated through thermodynamic insights and available data. The number of alternative processes is systematically reduced through a screening procedure until only feasible alternatives are obtained. As part of the methodology, process intensification involving reaction-separation tasks is also considered to improve the design by shifting the equilibrium reactions. Economic analysis and net present value are determined to find the best economically and operationally feasible process. The application of the methodology is presented through a case study involving biodiesel and fatty alcohol productions.
\end{abstract}

(c) 2013 Elsevier Ltd. All rights reserved.

\section{Introduction}

Presently, development of alternative energy sources has become important for sustainable and environmental reasons. Biodiesel is considered an alternative potential fuel to replace a petroleum diesel. It can be produced from local available renewable resources (e.g. vegetable oils and animal fats), so that the promotion of its use can decrease the dependence on a petroleum diesel (Ma \& Hanna, 1999).

Biodiesel consists of a fatty acid alkyl ester derived from the transesterification reaction of triglyceride, the major component in vegetable oils, and alcohol under the presence of an alkali catalyst for a conventional biodiesel production. Glycerol is found to be the byproduct of this process. Methanol is commonly used as a reactant because of its low cost and fast reaction rate (Lam, Lee, \& Mohamed, 2010) while various vegetable oils, such as soybean oil, palm oil, palm kernel oil and sunflower oil, can be used as feedstock. Since the price of crude vegetable oils changes over time, a biodiesel price is usually unstable. Moreover, the biodiesel price is closely related to the petroleum diesel price, which varies according to the worldwide market demand. To reduce any risk for biodiesel producers, who rely only on the biodiesel product, the use of chemicals obtained from the biodiesel production to synthesize other high value-added products has gained growing significance.

\footnotetext{
* Corresponding author. Tel.: +66 2 2186878; fax: +66 22186877

E-mail address: Amornchai.a@chula.ac.th (A. Arpornwichanop).
}

Fatty alcohol is among the important chemicals that are used for cosmetic and pharmaceutical industries. Instead of using petroleum-based feedstock, it can be synthesized from fatty acid alkyl ester obtained from the biodiesel production through a hydrogenation process (Dupont \& Simonet, 1991). The integration of fatty alcohol and biodiesel production results in a complicated process involving multi-components and products (e.g. triglycerides, free fatty acids, methanol, fatty acid methyl esters, fatty alcohols and glycerol) and various unit operations (e.g. reaction and separation units). This requires a systematic design methodology for synthesis of an optimal, efficient, flexible process in terms of operation and economics.

Presently, various methods for synthesis and design of chemical processes are available. The most commonly used method is heuristic by nature, which involves a set of rules for decision making in process design; choosing batch or continuous processes, designing vapor and liquid recovery systems, evaluating benefit of heat integration and determining separation system and sequence (Douglas, 1988). Kirkwood, Locke, and Douglas (1988) suggested that economic analysis should be taken in account in all design steps to reduce a number of process alternatives. Smith (2005) also proposed the onion diagram for decomposing the chemical process design into sub-layers so the number of reactors and separators can be reduced and the time demand for a preliminary process design is minimized. Seider, Seader, and Lewin (2004) proposed a step by step method for design of chemical processes. A set of criteria to be used to evaluate the process alternatives was proposed by Turton, Bailie, Whiting, and Shaeiwiz (2009). Alqahtani, Hellgardt, 
Holdich, and Cumming (2007) developed the design method for synthesis of reaction-separation-recycle systems. Since the physical and chemical properties of the involved chemical system play a very important role for the design/synthesis of a process, a thermodynamic insights based hybrid method to select the separation process was proposed by Jaksland, Gani, and Lien (1995). Hostrup, Gani, Kravanja, Sorsak, and Grossmann (2001) further developed this method by including a reverse design approach where process design variables are "back-calculated" for known design targets. The proposed method was applied to methyl acetate and cyclohexane productions. A reverse approach for process flowsheet design based on process knowledge, similar to knowledge of molecular structures, was proposed by d' Anterroches and Gani (2005). All these methods, however, focus on processes with one main product for a fixed reaction-catalyst and do not consider process alternatives in terms of diversion of resources to another product within the same overall process.

In this paper, a systematic step by step methodology is developed for design, synthesis and analysis of a flexible process that can economically produce multiple main products plus side products according to demand and economic state. The design methodology is applied for the production of biodiesel integrated with fatty alcohol and waste edible oil is employed as a feed source. According to the proposed methodology, a large number of alternative processes including all feasible separation techniques should be considered. All possible flowsheet configurations are first generated from a generic superstructure. Then through a systematic screening procedure, applying constraints in a hierarchical manner, the number of alternatives is reduced to identify only the feasible ones. These are further reduced in terms of productivity, consumption of raw material and process intensification. For the remaining alternatives, the optimal fractions (diversion of source) to produce multiple products are determined. As a result, a final step gives the best process which depends on economic criteria. Process intensification, such as reactive distillation, is applied to improve process performance in terms of productivity, energy consumption and economic criteria.

\section{Design methodology}

The objective of the methodology is to design a chemical process to convert a raw material, for example a renewable source, to multiple main products with associated side products. The main-steps of the methodology are shown in Fig. 1, where the work-flow is structured in terms of steps (1-7). After problem definition at Step 1 , search of available data (in a database as well as open literature) is made (Step 2), and based on this, the generic superstructure including the full set of available process alternatives is created at Step 3. Step 4 involves screening of alternatives and at the end of this step, only a few (5-10) alternatives are retained for further analysis. At Step 5, rigorous steady-state process simulations are performed before their performances are analyzed in Step 6. In the last Step 7 , process intensification is considered to improve the process performance. Details of each step in the methodology are described below:

\section{Step 1. Define problem}

The starting point is problem definition, where the number of available (renewable) sources, the number of desired main products, the number of side product, the qualities of the main products and the performance criteria for the desired process, among others, are defined as:

Objective:

Max or Min $F(X, Y)$
Subject to constraints:

$h(\mathrm{X})=0$

$g(X) \geq 0 \quad($ or $\quad<0)$

$\sum_{i=N 1_{k}}^{N 2_{k}} \mathrm{Y}_{i k}=1, \quad k=1, \mathrm{NS}$

where $F$ is the performance criteria, $X$ are the design variables (e.g. temperature, pressure and compositions), $Y$ are the binary integer (decision) variables corresponding to the existing streams, $h(\mathrm{X})$ are the set of equality constraints, such as process models (i.e. mass balance equations and energy equations), $g(X)$ indicates the set of process design specifications, $N 1_{k}$ and $N 2_{k}$ indicate the decision variable numbers involved in section $k$, and, NS is the total number of sections.

\section{Step 2. Search literatures/database}

At this step, search of available data (in a database as well as open literature) is made. Information on raw materials, main products, side products, reactions, catalysts, reaction conversion and operating conditions is gathered. The chemical and physical properties of substances existing in the process, such as solubility, vapor pressure, azeotropes, heat of vaporization, boiling point, critical properties and molar volume, are also important for generation of the process superstructure. Information of all available flowsheets are included in the superstructure generation (Step 3).

\section{Step 3. Generate superstructure from available data}

Based on all available data from Step 2, the generic superstructure is created as follows:

Step 3.1. Identify all components from reactions

All components in the reaction systems for different types of catalysts are listed as reactants, products (including side products) and inerts or impurities.

Step 3.2. Identify the properties of all components

The properties of all components, such as vapor pressure, heat of vaporization, boiling point, critical properties, etc., as well as formation of binary azeotropes between them are collected and used to select unit operations for separation tasks (Jaksland et al., 1995). When the needed component properties are not available or found in databases, the ProPred tool in the ICAS software (DiazTovar et al., 2011) is employed to predict them. For known binary azeotropic mixtures, if information about solvents is available, this is also included in the collected data.

Step 3.3. Find azeotrope of binary mixtures

For the binary pairs of components that may form azeotropes, the azeotrope temperature and composition are determined through VLE based calculations. When the azeotrope is found, use of solvent to separate the desired product is also considered. In general, selection of solvents depends on type of azeotropic mixture, i.e. minimum or maximum boiling azeotropes. In addition, the mixed feed of solvent and the binary mixture should be located in the same distillation region of the desired product (Hostrup, Harper, \& Gani, 1999) for extractive distillation. Various methods for solvent selection have been reported (for example, Hostrup et al., 1999; Mitrofanov, Sansonetti, Abildskov, Sin, \& Gani, 2012; Skouras, Kiva, \& Skogestad, 2005). In this work, the method and tool of Mitrofanov is employed. For solvent-less alternatives, changing operating pressure to shift the azeotrope is considered.

Step 3.4. Calculate binary ratio of properties

All components are ranked in increasing order for each property and the binary ratios of any property for adjacent components are computed. Repeating this for all properties, the binary ratio 


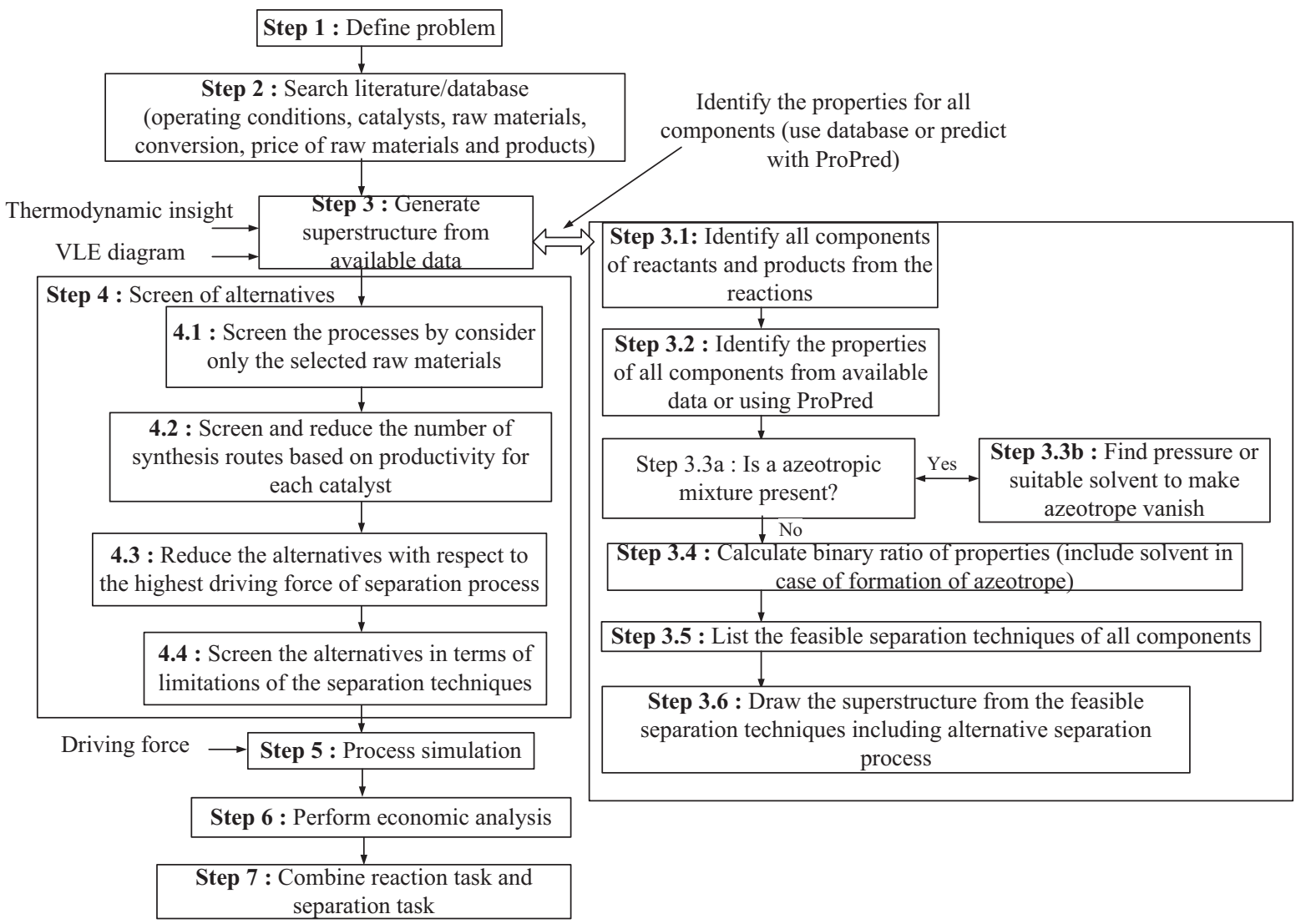

Fig. 1. Design methodology of the process producing two main products plus side products.

matrix of properties for all components is generated. The rows are the binary pairs of components and the columns are the property ratios.

Step 3.5. List the feasible separation techniques of all components

Separation techniques are selected by considering the adjacent binary ratios of properties (Jaksland et al., 1995). Table 1 shows the relationship of the separation technique and component properties.

Step 3.6. Superstructure generation

Based on the information collected, the superstructure is created together with the list of decision variables that will need to be determined. It is noted that process alternatives are generated by considering all separation techniques found feasible through the binary ratio matrix of properties and/or collected data (such as catalyst based reactions).

\section{Step 4. Screening of alternatives}

This step involves screening of alternatives, where process design constraints (see Eq. (2b)) are ordered in a hierarchical manner; the computationally easier constraints are considered first. Consequently, as the number of alternatives reduces, computationally more intensive constraints are considered. This step is divided into four sub-steps as follows:

Step 4.1. Screen the processes by considering only selected raw materials

Criteria for selection of raw materials are availability locally together with the lowest price.

Step 4.2. Screen and reduce the number of synthesis routes based on productivity of each catalyst

Since the productivity depends on the used catalysts and operating conditions, this step involves a fast screening process. The processes that give the highest productivity of main products for each catalyst type are only retained; thereby reducing the number of alternatives. In this step, the tasks involving reactions are considered.

Step 4.3. Reduce the alternatives with respect to the highest driving force of separation process

Separation techniques for various separation tasks are screened. For further reduction of alternatives, the adjacent binary pair corresponding to the highest ratio of properties computed in Step 3 is selected for the first separation task (Jaksland et al., 1995). Alternatively, the separation task could also be selected by considering the largest driving force of separation process from the further adjacent binary ratio. This step is repeated until the desired products are obtained. At the end of this step, the number of alternatives is reduced and the reduction of superstructure for the highest separation task is carried out. It is noted that when the binary ratios for vapor pressures and boiling points are the highest but the binary pairs also form azeotropes, solvent-based separation tasks are included in the list of feasible alternatives.

Step 4.4. Screen the alternatives in terms of limitations of the separation technique

In this step, the limitation of the separation technique is taken in account to reduce the process alternatives. For example, for an azeotropic binary pair, conventional distillation is removed because it cannot separate azeotropic mixtures. Separation by adsorption is removed if the temperature of operation is too high for the known adsorpbents that are usually quite sensitive to the temperature, or, a suitable adsorbent could not be found. Membrane-based separation is limited by limited flux and fouling problems.

\section{Step 5. Process simulation}

A large number of alternatives are eliminated from the above screening steps. The remaining alternatives that include feasible 
Table 1

Key pure component properties used to select the separation technique (Jaksland et al., 1995).

\begin{tabular}{|c|c|c|}
\hline Separation technique & Separation type & Pure component properties \\
\hline Absorption & Gas separation & Solubility parameter \\
\hline Azeotropic distillation & Vapor-liquid separation & Vapor pressure, formation of azeotropes, solubility parameter \\
\hline Crystallization & Solid-liquid separation & Melting point, heat of fusion at melting point \\
\hline Distillation & Vapor-liquid separation & Vapor pressure, heat of vaporization, boiling point \\
\hline Extractive distillation & Vapor-liquid separation & Vapor pressure, heat of vaporization, boiling point, solubility parameter \\
\hline Flash operation & Vapor-liquid separation & Vapor pressure, heat of vaporization, boiling point \\
\hline Gas separation membrane & Gas separation & Critical temperature, van der Waals volume \\
\hline Ion exchange & Liquid separation & Ion charge \\
\hline Liquid-liquid extraction & Liquid-liquid separation & Solubility parameter \\
\hline Liquid membrane & Liquid separation & Solubility parameter, molar volume, radius of gyration, affinity to carrier \\
\hline \multirow[t]{2}{*}{ Molecular sieve adsorption } & Gas separation & Kinetic diameter, van der Waals volume, \\
\hline & Liquid separation & polarizability, dipole moment \\
\hline Partial condensation & Vapor-liquid separation & Vapor pressure, heat of vaporization, boiling point \\
\hline Pervaporation & Vapor-liquid separation & Molar volume, solubility parameter, dipole moment \\
\hline Stripping & Vapor-liquid separation & Solubility parameter \\
\hline Supercritical extraction & Liquid-liquid separation & Solubility parameter, critical temperature, critical pressure \\
\hline
\end{tabular}

Table 2

Process variables and specifications needed for simulation.

\begin{tabular}{|c|c|c|}
\hline Unit operation & Process variables & Specification \\
\hline Reactor (stoichiometric conversion) & Temperature, pressure, flow rate & Reaction conversion \\
\hline Flash separator & Temperature, pressure, flow rate & Recovery of light key product (0.9) \\
\hline Distillation (one feed, two products) & $\begin{array}{l}\text { Reflux ratio, feed composition, number } \\
\text { of stage, feed stage, flow rate }\end{array}$ & $\begin{array}{l}\text { Recovery of light key }(0.99) \text { and } \\
\text { heavy key (0.99) products }\end{array}$ \\
\hline Decanter & Temperature, pressure, flow rate & \\
\hline
\end{tabular}

unit operations, such as reactor, flash operator, distillation and decanter within flowsheets, are simulated by using an appropriate process simulator (such as, ASPEN, PRO/II, HYSYS, ChemCAD or ICAS). Operating conditions, such as reaction temperature and pressure (determined in Steps 3-4), and other information, such as the reaction conversion, the amount of catalyst and the desired product specification (collected in Step 2), are used for these simulations. Table 2 lists the variables to be specified for each unit operation. A rigorous simulation is required in this step; therefore, thermodynamic model selection is also important.

In this study, a driving force based technique is used to design distillation columns by considering the energy consumption and total capital cost and using the reverse approach, the number of stages and the feed location that matches the driving force target are determined. The driving force of the two key components is defined as (Bek-Pedersen \& Gani, 2004):

$F_{i j}=y_{i}-x_{i}=\frac{x_{i} \beta_{i j}}{1+x_{i}\left(\beta_{i j}-1\right)}-x_{i}$

where $F_{i j}$ is the driving force, $y_{i}$ is the composition in the vapor phase, $x_{i}$ is the composition in the liquid phase and $\beta_{i j}$ is the relative volatility of components $i$ and $j$.

Step 6. Perform economic analysis

Remaining processes are analyzed based on an economic indicator. Since a net present value (NPV) gives the present value of all payments and provides a basis for process comparison, it is used as an economic criterion to find the best economic process. The Guthrie's modular method is used to evaluate the capital costs of equipment.

It is noted that the proposed design methodology is generic in nature (can handle any number of main products) and flexible (method of solution can be changed through another order of constraints, including all at the same time). Note, however, in this paper the option for two main products and a fixed hierarchical order for constraints is used.

\section{Step 7. Combine the reaction task and separation task}

For the best alternative process that is obtained from Step 6 , a process intensification option involving the reaction and separation tasks is further considered. In general, there are many types of process intensification, such as reactive crystallization, reactive flash, reactive distillation, and reactive absorption. The objective here has been to consider process intensification only when reaction followed by separation could be combined into one operation. It is beyond the scope of this paper to develop a comprehensive intensified process. However, integration of the method proposed by Lutze, Román-Martinez, Woodley, and Gani (2012) with this methodology could be considered in future work. In this study, a reactive distillation in which the reaction and separation occur at the same time is employed to improve the designed process by shifting the equilibrium reactions (Georgiadis, Schenk, Gani, \& Pistikopoulos, 2002). Fig. 2 shows the criteria used to determine whether a combination of separation and reaction tasks should be performed by using the reactive distillation. Table 3 summarizes tools and methods that are employed in each step of the design methodology.

\section{Case study}

The application of the design methodology is presented though a case study involving the production of biodiesel integrated with fatty alcohol. Glycerol is regarded as a major by-product of the biodiesel production process. Another option to use glycerol as a fuel to produce hydrogen for fatty alcohol production is also considered.

\section{Step 1. Define problem}

Here, the defined problem is to produce biodiesel and fatty alcohol at a purity of $99.5 \mathrm{wt} \%$. Glycerol is considered the by-product. The performance criterion is to maximize the net present value (NPV) of the process. Thus, the problem can be mathematically described as follows:

Objective function

$\operatorname{Max} \mathrm{NPV}=f(X, Y)$ 


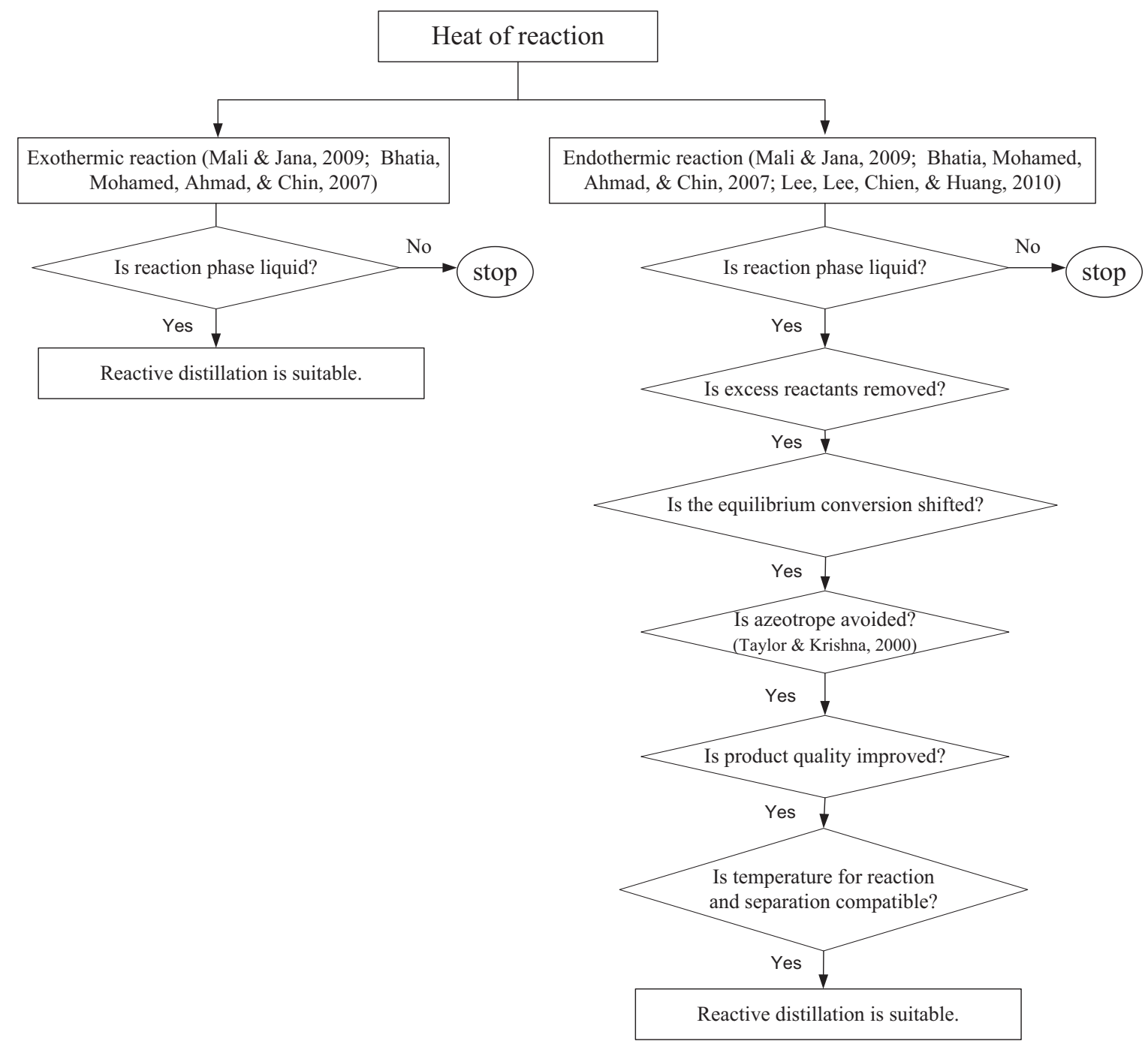

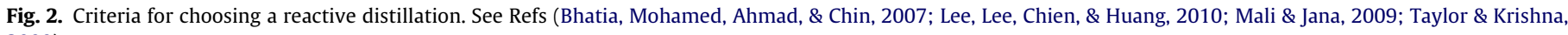
2000).

$$
\begin{aligned}
\mathrm{NPV}= & {\left[\left(F_{\mathrm{bio}} P_{\mathrm{bio}}+F_{\mathrm{fat}} P_{\mathrm{fat}}+F_{\mathrm{gly}}+P_{\mathrm{gly}}\right)(P / A(i, n))-\left(F_{\mathrm{oil}} P_{\mathrm{oil}}\right.\right.} \\
& +F_{\mathrm{met}} P_{\mathrm{met}}+F_{\mathrm{cat}} P_{\text {cat }}+F_{\mathrm{H} 2} P_{\mathrm{H} 2}(P / A(i, n))-\left(Q_{\text {reactor }} P_{\text {steam }}\right. \\
& \left.+Q_{r, i} P_{\text {stam }}+Q_{C, i} P_{\text {steam }}+Q_{\mathrm{elec}} P_{\text {elec }}\right)(P / A(i, n)) \\
& \left.-D(P / A(i, n))-\Sigma Y_{i} C(X, a)\right]
\end{aligned}
$$

subject to

$$
\begin{aligned}
& h_{1}(X)=0 \\
& h_{2}(X)=0 \\
& g_{1}(X) \geq p_{1} \\
& g_{2}(X) \geq p_{2} \\
& p_{1}=99.5 \text { wt } \% \\
& p_{2}=99 \text { wt } \% \\
& \sum_{i=N 1_{k}}^{N} Y_{i k}=1, \quad k=1, \quad \mathrm{NS}
\end{aligned}
$$

where $X$ is the vector of process variables, such as flow rate, pressure and temperature, $h_{1}(X)$ is the mass balance, $h_{2}(X)$ is the energy balance, $g_{1}(X)$ and $g_{2}(X)$ define the process specifications,
$Y$ are the binary integer (decision) variables, $\mathrm{a}$ is the equipment size, such as diameter, height and heat exchanger area, $S$ are the costs of maintenance, insurance and laboratory, $P$ are the material and energy prices, such as biodiesel, fatty alcohol, glycerol and catalyst, $Q$ is the heat duty, $F$ is the flow rate, $C$ is the capital cost of equipment, $P / A$ is the present worth factor, $i$ is the interest rate and $n$ is the project life.

The NPV includes the total capital investment, revenues, and depreciation $(D)$ and operating costs and is determined based on the interest rate of $15 \%$ and the lifetime of 20 years.

\section{Step 2. Search literatures/database}

At this step, the properties of chemicals involving the biodiesel and fatty alcohol productions are collected. These chemicals include protriglycerides (e.g. trilaurin (C12), trimyristin (C14), tripalmitin (C16), tristearin (C18), triolein (C18 with single double bond), trilinolein ( 18 with two double bonds), trilinolenin (C18 with three double bonds)), methanol, free fatty acids (e.g. lauric acid, myristic acid, palmitic acid, stearic acid, oleic acid, linoleic acid, linoleninc acid), methyl esters (e.g. methyl laurate, methyl myristate, methyl palmitate, methyl stearate, methyl oleate, methyl linoleate, methyl linolenate) (Chang \& Liu, 2010). The missing data are estimated based on thermodynamic models.

According to a literature review, it is found that there are 54 different catalysts applied for biodiesel production using 
Table 3

Summary of tools and methods used in the design methodology.

\begin{tabular}{|c|c|c|}
\hline Step & Tools & Methods \\
\hline 1. Define problem & - & Define the objective function of problem \\
\hline 2. Search literatures/database & $\begin{array}{l}\text { Available data reported in journals and open } \\
\text { sources }\end{array}$ & \\
\hline $\begin{array}{l}\text { 3. Generate superstructure from } \\
\text { available data }\end{array}$ & $\begin{array}{l}\text { - Thermodynamic insights } \\
\text { - CAPEC databases of oil } \\
\text { - ProPred } \\
\text { - Simple mass balance }\end{array}$ & $\begin{array}{l}\text { - Calculate adjacent binary properties ratio } \\
\text { - Azeotrope information } \\
\text { - List the alternative separation techniques } \\
\text { - List the possible biodiesel production with different } \\
\text { catalysts and fatty alcohol production } \\
\text { - Generate superstructure }\end{array}$ \\
\hline $\begin{array}{l}\text { 4.1 Screen the processes by considering } \\
\text { only selected raw materials }\end{array}$ & Price of raw materials & Select interesting raw material \\
\hline $\begin{array}{l}\text { 4.2 Screen and reduce the number of } \\
\text { synthesis routes based on productivity } \\
\text { for each catalyst }\end{array}$ & Simple mass balance & Calculate productivity ( $\mathrm{kg}$ of mass product $/ \mathrm{kg}$ of mass oil) \\
\hline $\begin{array}{l}\text { 4.3 Reduce the alternatives with respect to } \\
\text { the highest driving force of separation } \\
\text { process }\end{array}$ & Thermodynamic insight & $\begin{array}{l}\text { Choose the separation technique with the highest driving } \\
\text { force }\end{array}$ \\
\hline $\begin{array}{l}\text { 4.4 Screen the alternatives in terms of } \\
\text { limitations of the separation technique }\end{array}$ & LLE & \\
\hline 5. Process simulation & $\begin{array}{l}\text { - Driving force diagram } \\
\text { - Process simulator }\end{array}$ & $\begin{array}{l}\text { Use the driving force method to obtain the optimum } \\
\text { conditions of separation process such as reflux ratio, } \\
\text { optimum total stages and feed location which minimize } \\
\text { the energy consumption }\end{array}$ \\
\hline 6. Perform economic analysis & $\begin{array}{l}\text { - Cost of raw materials, capital cost and } \\
\text { operating cost } \\
\text { - Product prices }\end{array}$ & $\begin{array}{l}\text { - Calculate the profitability (NPV) } \\
\text { - Perform sensitivity analysis of NPV with respect to raw } \\
\text { material price and product prices } \\
\text { - Determine the fraction of product one to produce } \\
\text { product two which gives the highest profitability }\end{array}$ \\
\hline
\end{tabular}

different types of vegetable oils and they can be classified in terms of alkali catalyst, acid catalyst, solid base catalyst, solid acid catalyst, enzyme catalyst. The main reaction for biodiesel production consists of the three-step transesterification of triglyceride, diglyceride and monoglyceride with methanol. In addition, biodiesel can be produced under methanol supercritical condition. In case of using vegetable oils with high free fatty acid content, a two-step biodiesel production consisting of the hydrolysis and esterification processes is considered; 13 different catalysts used in the hydrolysis process are reported. For fatty acid production, there are two approaches; firstly, the mixed methyl esters from biodiesel production are hydrogenated and the mixed fatty alcohol produced is then separated (Approach 1), and secondly, the mixed methyl esters are separated before hydrogenation (Approach 2 ).

Information on the operating conditions and reaction conversion is also collected at this step and they are included as Supplementary material.

\section{Step 3. Generate superstructure from available data}

Step 3.1. Identify all components from reactions

A mixture of triglycerides in vegetable oils, such as trilaurin, trimyristin, tripalmitin, tristearin, triolein, trilinolein and trilinolenin, are identified. Diglycerides and monoglycerides including dilaurin, dimyristin, dipalmitin, distearin, diolein, dilinolein, dilinolenin, monolaurin, monomyristin, monopalmitn, monostearin, monoolein, monolinolein and monolinolenin are intermediates generated from the biodiesel production process. In addition to triglycerides, vegetable oils also contain free fatty acids (e.g. lauric acid, myristic acid, palmitic acid, oleic acid, linoleic acid and linolenin acid). Biodiesel product consists of a mixture of methyl esters, such as methyl laurate, methyl myristate, methyl palmitate, methyl stearate, methyl oleate and methyl linoleate. Methyl esters can be produced via the hydrogenation process to produce fatty alcohols, e.g. lauryl alcohol, myristyl alochol, cetyl alcohol, stearyl alcohol, oleyl alcohol, linoleyl alcohol and linolenyl alcohol. Other substances in the biodiesel integrated with fatty alcohol production are methanol, glycerol, water, and hydrogen.

Step 3.2. Identify the properties of all components

In this step, information on the properties of all components in the biodiesel and fatty alcohol production systems, as previously mentioned, are collected and they given as Supplementary material.

Step 3.3. Find azeotrope of binary mixtures

The UNIQUAC model option in HYSYS is used to describe thermodynamic properties and VLE diagrams for all binary systems are generated (Zhang, Dube, McLean, \& Kates, 2003). Fig. 3 shows an example of the VLE diagram between methyl myristate and methyl palmitate at $4 \mathrm{kPa}$. In this figure, the model prediction is also compared with experimental data (Silva, Falleiro, Meirelles, \& Krahenbuhl, 2011) to confirm the reliability of the thermodynamic models used in this study. Figs. 4 and 5 show the VLE diagrams between glycerol/methyl laurate and glycerol/lauric

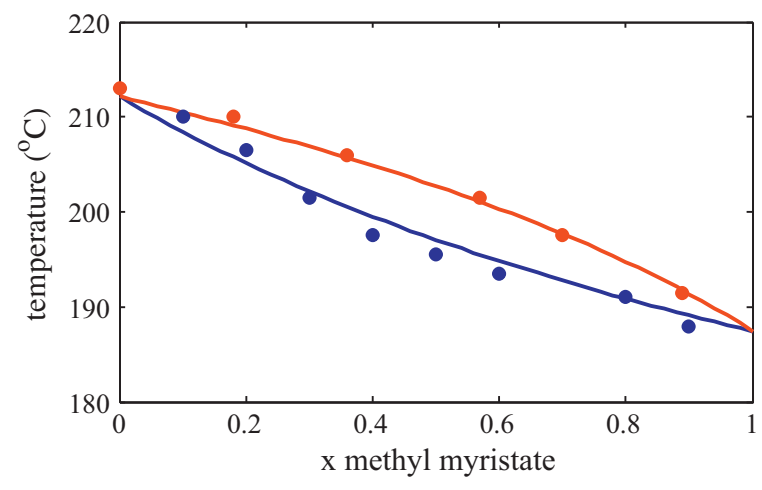

Fig. 3. VLE diagram between methyl myristate and methyl palmitate. 


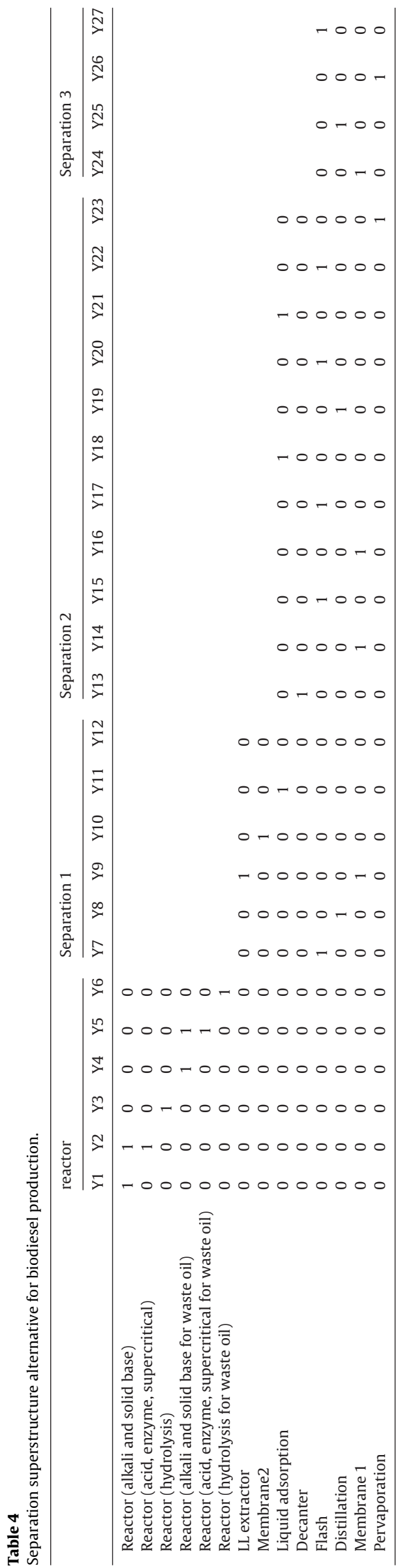

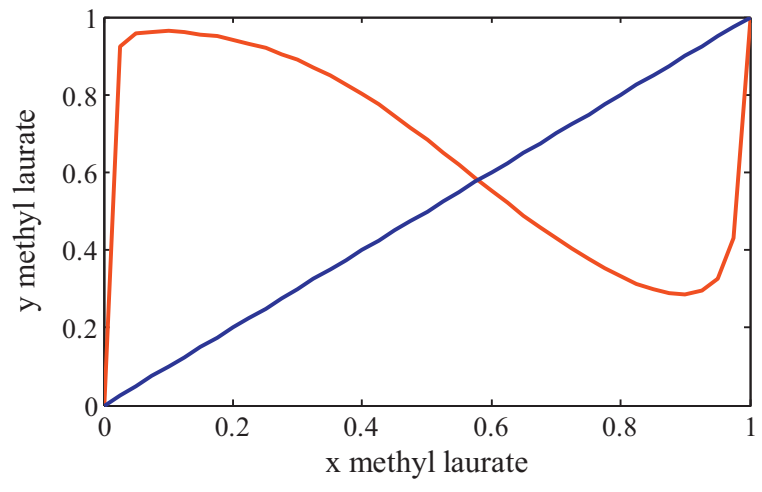

Fig. 4. VLE diagram between glycerol and methyl laurate.

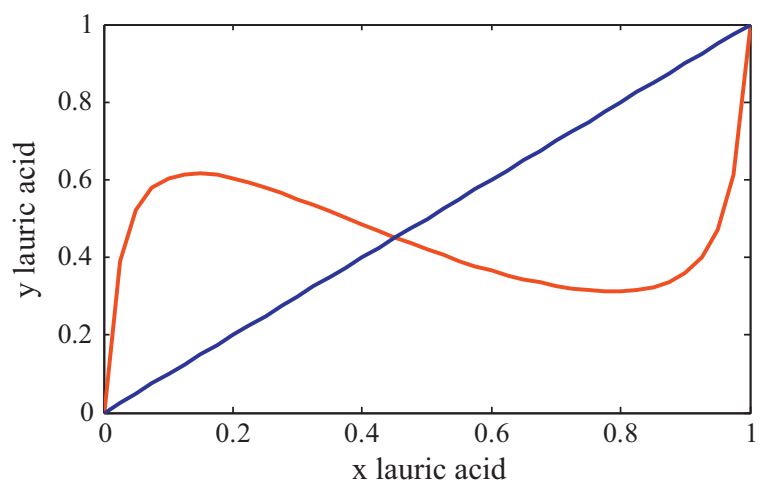

Fig. 5. VLE diagram between glycerol and lauric acid.

acid, respectively, and indicate a formation of azeotropic mixtures. The azeotrope formation is verified to be at a mole fraction of methyl laurate $=0.58$ for the mixture of methyl laurate and glycerol at a temperature of $506.39 \mathrm{~K}$ and pressure of $101.3 \mathrm{kPa}$. Thus, pure methyl laurate cannot be separated from glycerol by using a conventional distillation when the mole fraction of methyl laurate is lower than 0.58 . However, the product composition is not been known at this step and so a final decision has not been made. Another option is to consider liquid phase split and Fig. 5 confirms the existence of two-liquid regions for the glycerol and lauric acid system. For this case, liquid miscibility is a key parameter and a decanter is used for separating these mixtures. Step 3.4. Calculate binary ratio of properties

For the identified chemicals present in the system, binary ratios of properties, such as vapor pressure, melting point, boiling point, solubility and molecular weight, for all components are computed and they can be obtained from the authors.

Step 3.5. List the feasible separation techniques of all components

From the binary ratio of properties, feasible separation techniques of all components are obtained for biodiesel production and for fatty alcohol production. The tables with the binary pairs and their corresponding lists of feasible separation techniques for biodiesel and fatty alcohol productions are given as Supplementary material.

Step 3.6. Superstructure generation

Using the collected data, a superstructure for the production of biodiesel integrated with fatty alcohol is generated (Fig. 6). The superstructure contains six separation operation types (flash separator, decanter, distillation, stripper, absorber and membrane), three types of conversion reactors (transesterification reactor, esterification reactor and hydrolysis reactor - one for each type of catalyst considered) and seven types of catalysts $\left(\mathrm{NaOH}, \mathrm{H}_{2} \mathrm{SO}_{4}\right.$, $\mathrm{KOH} / \mathrm{Al}_{2} \mathrm{O}_{3}$, DTPA/clay, $\mathrm{\kappa}$-carrageenan, supercritical methanol, 


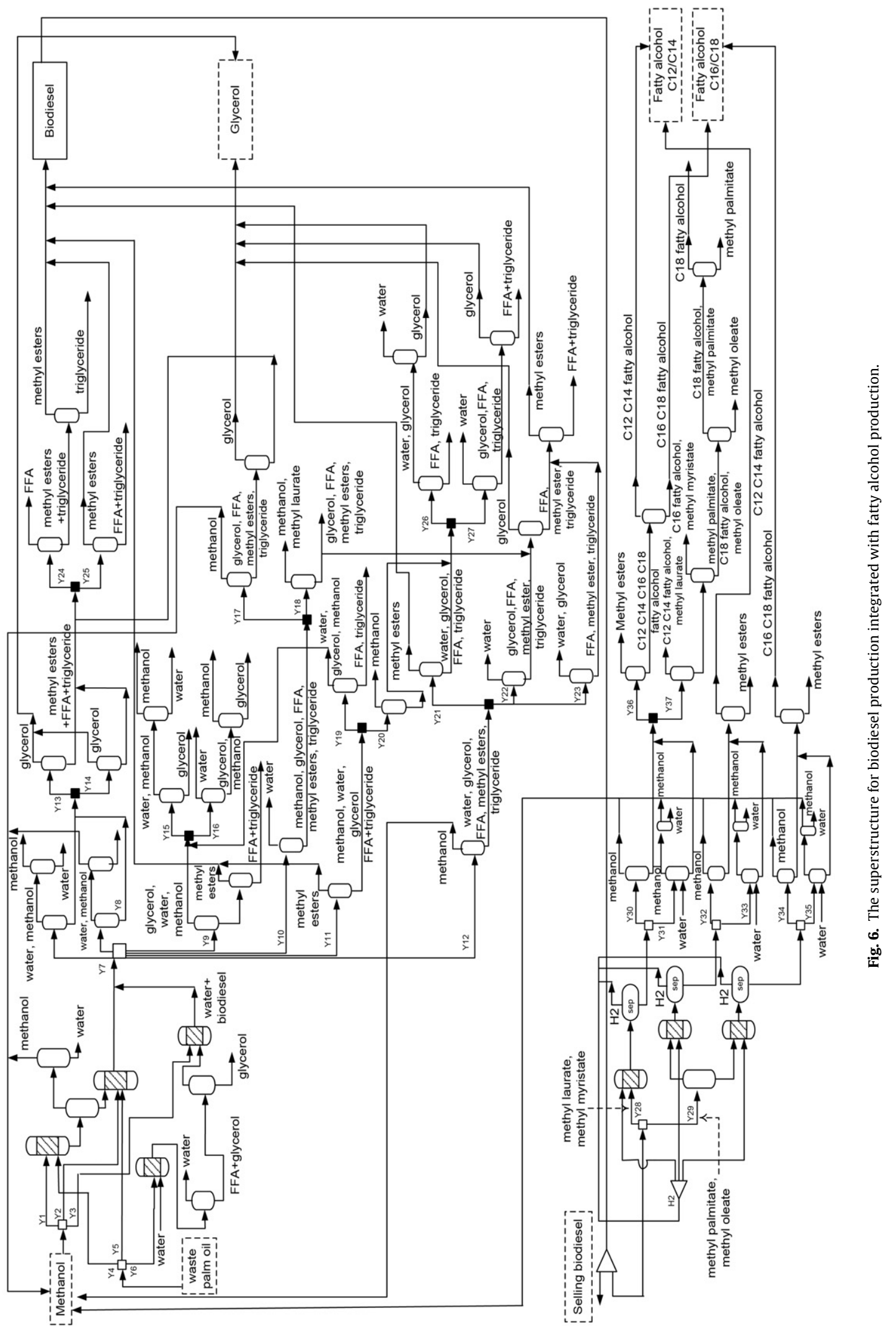




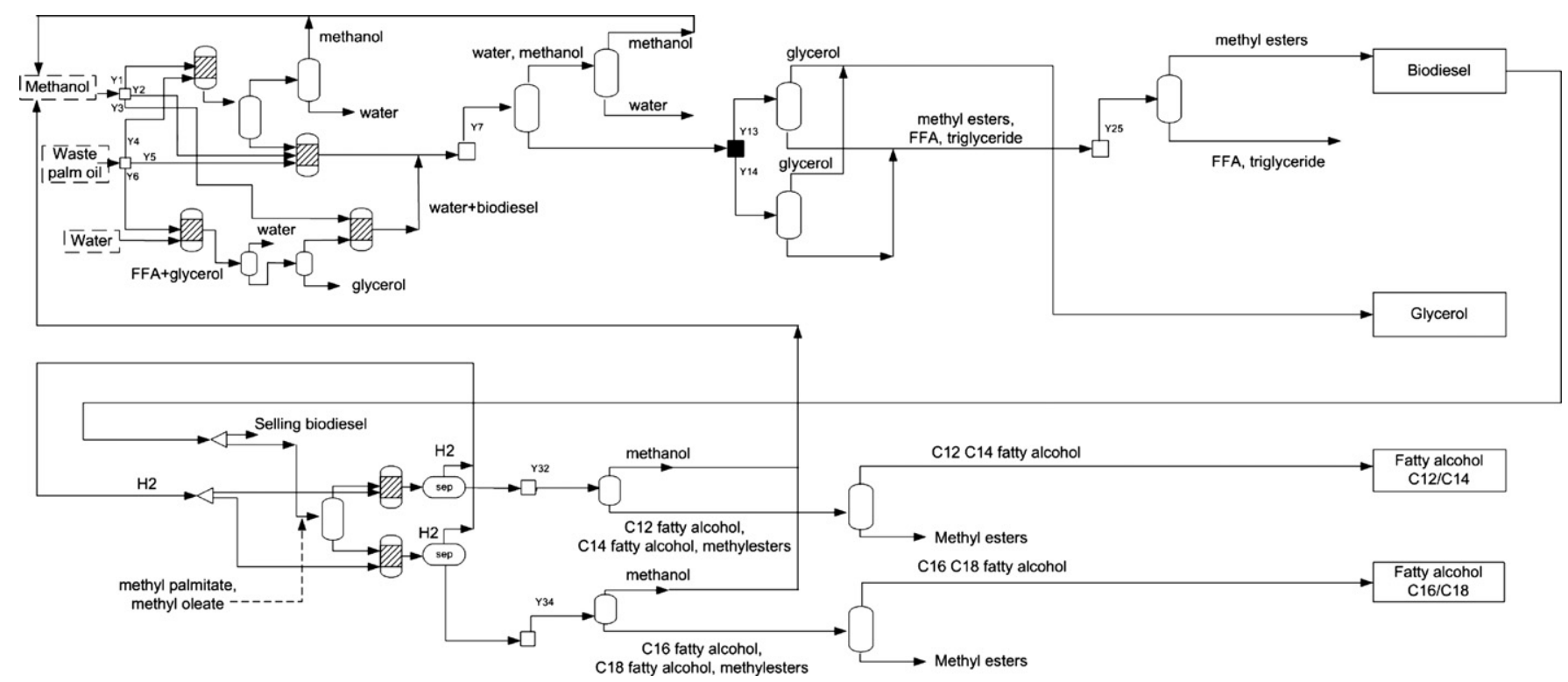

Fig. 7. The flowsheet of alternative processes for biodiesel production integrated with fatty alcohol production (based on the largest driving force).

Table 5

Separation superstructure alternative for fatty alcohol production.

\begin{tabular}{|c|c|c|c|c|c|c|c|c|c|c|}
\hline & \multicolumn{2}{|c|}{ Reactor or separation } & \multicolumn{6}{|c|}{ Separation 1} & \multicolumn{2}{|c|}{ Separation 2} \\
\hline & Y28 & Y29 & Y30 & Y31 & Y32 & Y33 & Y34 & Y35 & Y36 & Y37 \\
\hline Reactor & 1 & 0 & & & & & & & & \\
\hline Spliter & 0 & 1 & & & & & & & & \\
\hline Flash & 0 & 0 & 1 & 0 & 1 & 0 & 1 & 0 & & \\
\hline LL extractor & 0 & 0 & 0 & 1 & 0 & 1 & 0 & 1 & & \\
\hline Distillation & 0 & 0 & 0 & 0 & 0 & 0 & 0 & 0 & 0 & 1 \\
\hline Liquid adsorption & 0 & 0 & 0 & 0 & 0 & 0 & 0 & 0 & 1 & 0 \\
\hline
\end{tabular}

lipase). The binary integer variables $\left(Y_{i k}\right)$, as shown in Fig. 6, indicate the available alternatives. It is noted that when $Y_{i k}$ is zero, it means that the alternative is not considered. The full set of alternatives is 342,144 . Tables 4 and 5 show the feasible set of alternatives for biodiesel and fatty alcohol productions, respectively.

\section{Step 4. Screen of alternatives}

Step 4.1. Screen the processes by considering only selected raw materials

In this study, waste cooking palm oil is selected as a renewable source for biodiesel production. Thus, the number of alternatives is reduced at this step to 95,040.

Step 4.2. Screen and reduce the number of synthesis routes based on productivity for each catalyst

Productivities of biodiesel and fatty alcohol productions are used as the criteria to reduce the number of alternatives. It is noted that seven biodiesel production processes based on different catalysts and two fatty alcohol production processes as mentioned earlier have been considered. Table 6 shows the

\section{Table 6}

Productivity of biodiesel production using different catalysts and fatty alcohol production (approach 2).

\begin{tabular}{lll}
\hline Biodiesel production & $\begin{array}{l}\text { Productivity of } \\
\text { biodiesel }\end{array}$ & $\begin{array}{l}\text { Productivity of } \\
\text { fatty alcohol }\end{array}$ \\
\hline (1) $\mathrm{NaOH}$ (base cat.) & 0.95 & 0.893 \\
(2) $\mathrm{H}_{2} \mathrm{SO}_{4}$ (acid cat.) & 0.95 & 0.893 \\
(3) $\mathrm{KOH} / \mathrm{Al}_{2} \mathrm{O}_{3}$ (solid base cat.) & 0.92 & 0.893 \\
(4) $\mathrm{DTPA} /$ clay (solid acid cat.) & 0.955 & 0.896 \\
(5) $\mathrm{K}$-Carrageenan (enzyme process) & 0.99 & 0.894 \\
(6) Supercritical methanol & 0.94 & 0.894 \\
(7) Lipase (hydrolysis process) & 0.91 & 0.894 \\
\hline
\end{tabular}

biodiesel and fatty alcohol productivities obtained from different biodiesel processes. At the end of this step, the number of alternatives is reduced to 7392 .

Step 4.3. Reduce the alternatives with respect to the highest driving force of separation process

Most preferable separation technique is selected based on the highest value of binary ratio of properties, indicating the highest driving force of a separation task and possibly the lowest energy consumption required for this separation technique. The reduced superstructure of biodiesel production integrated with fatty alcohol production is shown in Fig. 7. The number of alternatives is reduced to 14 at this step.

Step 4.4. Screen the alternatives in terms of limitations of the separation technique

At this step, the limitations on separation tasks are taken into account in the screening process. For example, when considering the separation of glycerol from biodiesel, it is found that a decanter is a suitable process due to a high binary ratio of their solubility. However, methanol has a negative effect on this phase separation. For this case, methanol should be first removed from the biodiesel product before separating glycerol. At the end of this step, the number of alternative is reduced to seven.

According to the generated superstructure, the waste palm oil consisting of mixed triglycerides with free fatty acids are sent to the pre-reactor (if alkali catalyst and heterogeneous base catalyst are used) or sent to the main reactor (if acid catalyst, heterogeneous acid and enzyme catalysts, supercritical methanol are used) to produce the mixed methyl esters (biodiesel) and glycerol. Alternatively, the waste palm oil is first hydrolyzed with water and the product obtained (mixed fatty acids) is sent to the esterification reactor to produce the mixed methyl esters. In this 

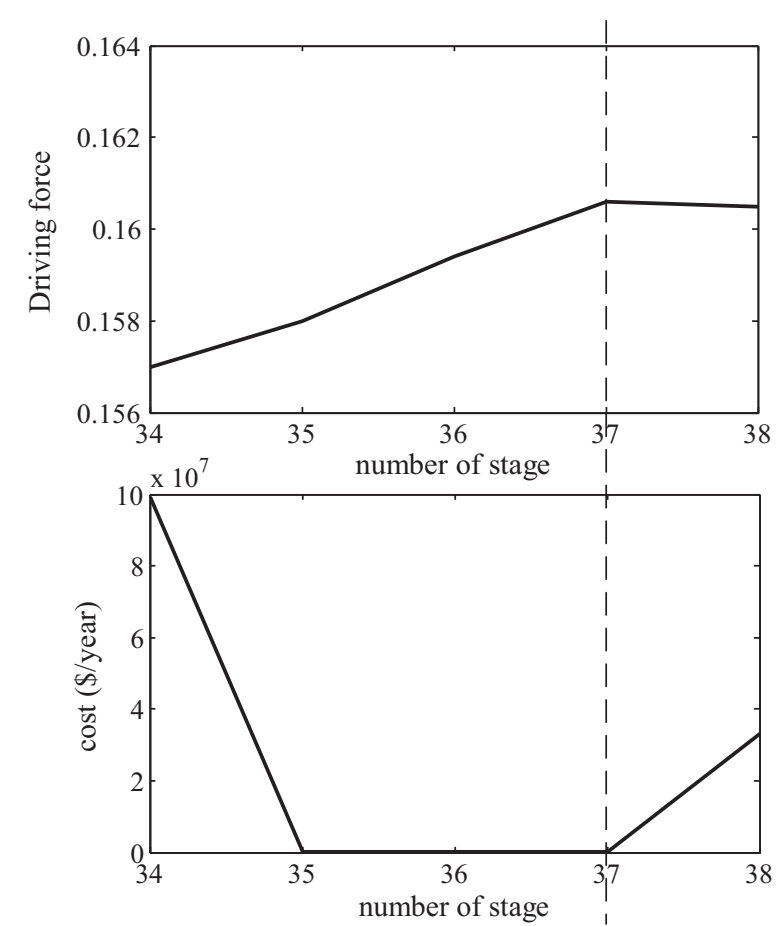

Fig. 8. Effect of the number of total stages of distillation for separating methyl myristate from methyl palmitate on the total annual cost (\$/year).

case, all the products and unreacted raw materials are sent to the flash separator. The light products including water and methanol are separated by a distillation column while the heavy products (methyl esters) are sent to the decanter to separate the light phase (mixed methyl ester and methanol) and the heavy phase (water, glycerol and methanol). The purified mixed methyl esters are obtained from the distillation column. The mixed methyl esters are split into two streams: one for biodiesel product and the other for fatty alcohol production. To produce fatty alcohol, the methyl esters are sent to the hydrogenation reactor. Excess hydrogen is separated by flash separator. The final products are C12-C14 fatty alcohol and C16-C18 fatty alcohol.

\section{Step 5. Process simulation}

Rigorous steady state process simulations of all remaining feasible process alternatives are performed (HYSYS has been used) before their corresponding performance criteria are computed in Step 6 for economic analysis and final selection. In the process simulation step, a waste palm oil consisting of a mixture of triglycerides (e.g. trilaurin, trimyristin, tripalmitin, tristearin, triolein, trilinolein and trilinolenin) and free fatty acid (e.g. lauric acid, myristic acid, palmitic acid, stearic acid, oleic acid, linoleic acid and linolenin acid) is used as a feedstock to produce biodiesel. The UNIQUAC model is used for the liquid-phase activity coefficients and the vapor phase has been assumed to be ideal, while the percentage recoveries of flash separators and distillations are specified at $90 \%$ and $99 \%$, respectively. Reaction conditions for the biodiesel and fatty alcohol production processes are shown in Table 7. The driving force technique is used to design distillation columns by considering the energy consumption and total capital cost and using the reverse approach, the number of stages and feed location that match the driving force target are determined. The optimum number of stages and feed stage of the distillation column for separating methyl myristate from methyl palmitate under the highest driving force condition is shown in Figs. 8 and 9, respectively. It can be seen that a minimum total cost can be achieved when the optimum feed stage and total stage are selected due to the tradeoff between the capital cost and the energy cost.
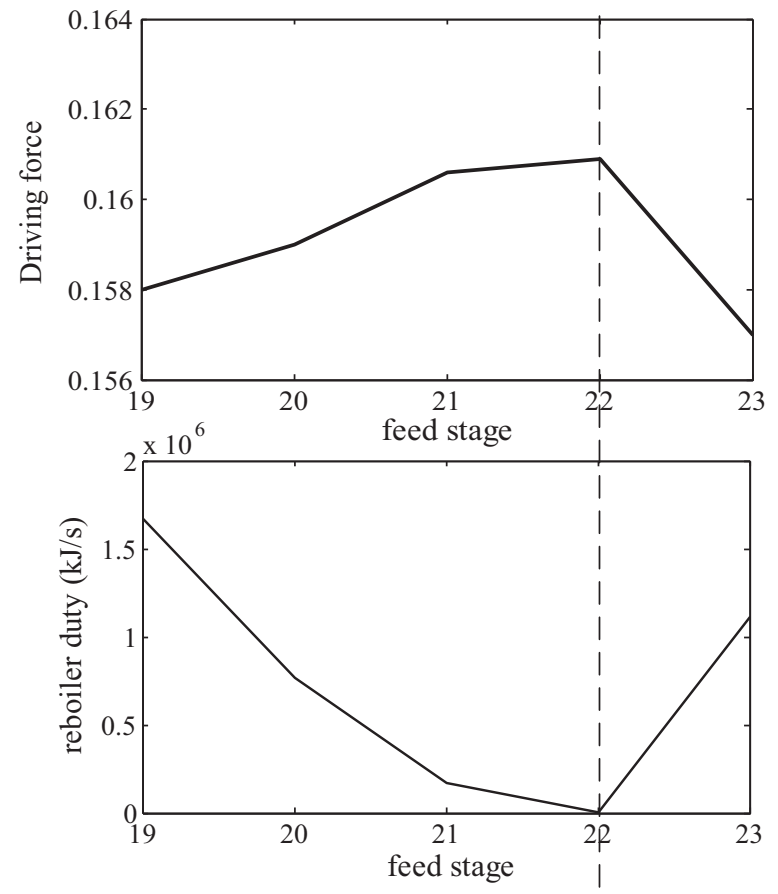

Fig. 9. Effect of the feed stage location of distillation for separating methyl myristate from methyl palmitate on the reboiler heat duty (Btu/h).

\section{Step 6. Perform economic analysis}

Seven processes are analyzed through profitability indicators such as a net present value (NPV). The following assumptions were made to determine the NPV; interest rate is $15 \%$, a linear depreciation and no discount payback period are assumed, salvage value is neglected and project life is 20 years.

The results show that all the processes are economically feasible because of the positive NPV. In addition, the NPV increases with increasing fraction of biodiesel to produce fatty alcohol. The heterogeneous acid process for biodiesel production shows the highest NPV value due to its high revenue and low total production costs, whereas the alkali catalyzed process has low total investment cost. The effect of the fraction of biodiesel to produce fatty alcohol on the NPV is shown in Fig. 10. At the end, the best process is found to be the heterogeneous acid catalyzed process and the suitable fraction of biodiesel to produce fatty alcohol is 1. That is, most of biodiesel should be diverted to fatty alcohol because the price of fatty alcohol is higher than biodiesel (note that this is a constrained optimal solution and by adding a maximum amount of allowed diversion of biodiesel, both main products can be obtained). Tables with the results in terms of operational

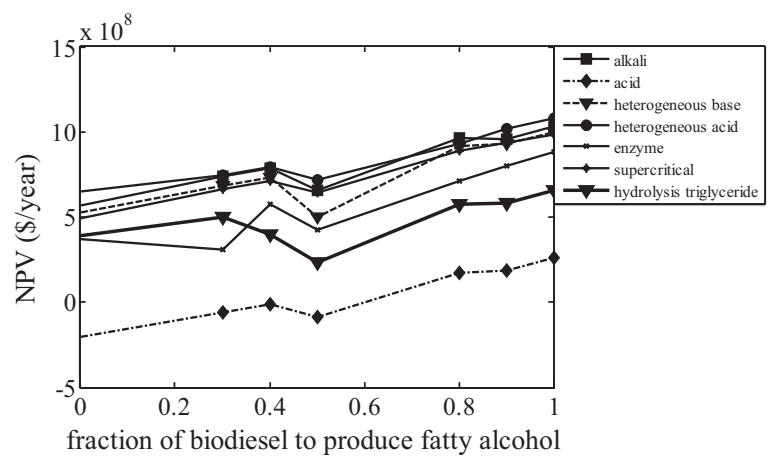

Fig. 10. Effect of the fraction of biodiesel to produce fatty alcohol on NPV (\$/year). 
Table 7

Operating conditions and performance of the transesterification reactor using different catalysts.

\begin{tabular}{|c|c|c|c|}
\hline Catalyst & $T\left({ }^{\circ} \mathrm{C}\right)$ & $P($ atm $)$ & Conversion $(\%)$ \\
\hline \multicolumn{4}{|l|}{ Biodiesel production } \\
\hline NaOH (base cat.) (Narváez, Rincón, \& Sánchez, 2007) & 60 & 1 & 94.3 \\
\hline $\mathrm{H}_{2} \mathrm{SO}_{4}$ (acid cat.) (Wang, Ou, Liu, Xue, \& Tang, 2006) & 130 & 1 & 90 \\
\hline $\mathrm{KOH} / \mathrm{Al}_{2} \mathrm{O}_{3}$ (heterogeneous base cat.) (Noiroj, Intarapong, Luengnaruemitchai, \& Jai-In, 2009) & 70 & 1 & 91.7 \\
\hline DTPA/clay (heterogeneous acid cat.) (Bokade \& Yadav, 2009) & 70 & 17 & 94 \\
\hline к-Carrageenan (enzyme) (Jegannathan, Seng, \& Ravindra, 2011) & 30 & 1 & 99 \\
\hline Supercritical methanol (Song, Lim, Lee, \& Lee, 2008) & 350 & 40 & 95 \\
\hline Hydrolysis (Serri, Kamarudin, \& Abdul Rahaman, 2008) & 45 & 1 & 95 \\
\hline \multicolumn{4}{|l|}{ Fatty alcohol production } \\
\hline CuCr (Fleckenstein, Pohl, \& Carduck, 1991) & 250 & 50 & 99 \\
\hline
\end{tabular}

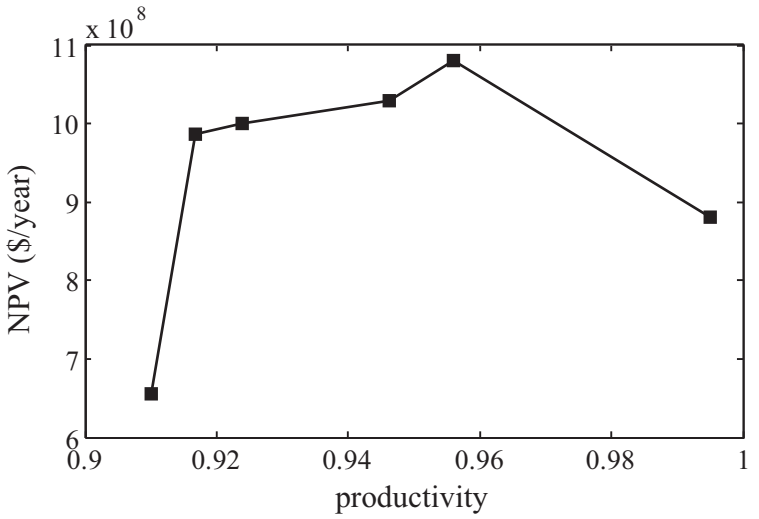

Fig. 11. Effect of biodiesel productivity on NPV (\$/year).

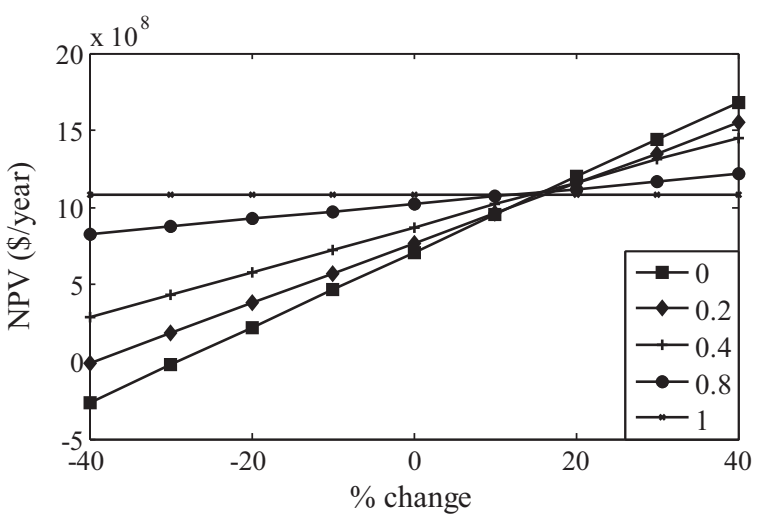

Fig. 12. Effect of changes in the biodiesel price on NPV with different fraction of biodiesel to produce fatty alcohol.

variables, equipment sizing parameters, equipment costs, etc., are given as Supplementary material.

Fig. 11 shows the effect of productivity on NPV. The NPV increases with increasing the productivity and reaches its maximum value; there is a trade-off between the productivity and the $\mathrm{NPV}$. When considering the fraction of biodiesel to produce fatty alcohol, it is found that the suitable fraction can be changed when the biodiesel price increases higher than 20\% (Fig. 12).

Table 8 summarizes the results for screening procedure in the proposed design methodology.

\section{Step 7. Combine the reaction task and separation task}

In the last step of the methodology, a process intensification of the best biodiesel production process obtained from the previous step is considered to improve its performance. In this study, a reactive distillation where reaction and separation tasks are carried out in a single unit is applied to the biodiesel process. Combining separation of water and methanol from biodiesel with the reaction step to improve the conversion of equilibrium-limited reaction has been considered. It is assumed that as the reaction reaches equilibrium condition, the number of total stages is five (including condenser and reboiler), feed location of the mixed triglycerides and methanol is the second stage and the feed ratio of methanol to triglycerides is 4.5. Methanol and water are obtained at the top of the column, while methyl esters and glycerol are obtained at the bottom. The results with and without process intensification are compared in Table 9. Due to its low fraction, water derived from the esterification process (the pre-treatment section of waste palm oil) is assumed to be an inert component. From the element concept, there are 4 components with 3 elements; free fatty acids and water are neglected due to their low fractions. The ternary reactive phase diagram of the transesterification process for a biodiesel production system at $438 \mathrm{~K}$ is shown in Fig. 13. It shows that pure methyl ester is obtained at $W_{\mathrm{A}}$ and $W_{\mathrm{B}}$ of $50 \%$, at $\mathrm{AB}$ point, while pure triglyceride is obtained at $W_{\mathrm{A}}$ and $W_{\mathrm{C}}$ of $50 \%$ at $A C$ point. This implies that methyl ester, methanol and glycerol are found at the bottom of the reactive distillation column. As the $W_{\mathrm{A}}$ and $W_{\mathrm{B}}$ do not equal to $50 \%$ at the end of the liquid line, the bottom product is not pure methyl ester; methanol is mixed with the biodiesel product. It is known that transesterification is an endothermic reaction; therefore, an increase in the operating temperature moves the liquid line closer to $W_{\mathrm{A}}$ and $W_{\mathrm{B}}$ of $50 \%$. From the simulation results, the element fraction at the bottom of the column is at $\mathrm{E}$ point while the element fraction at the top is element $B$ that is pure methanol. This means that the separation task of the reactive distillation cannot separate excess reactant from the product; therefore, biodiesel product is mixed with methanol and glycerol. Other separation techniques, such as distillation and flash, are required for purification of biodiesel. Although the reactive distillation cannot separate the light product (methanol and glycerol) from the heavy product (methyl esters), it can improve the biodiesel process by increasing the biodiesel production rate.

As previously mentioned, glycerol can be used for the production of hydrogen, which is used in the synthesis of fatty alcohol, instead of specifying it as a by-product of the biodiesel production. This option of using the glycerol is also considered and the developed design methodology is applied. Thus, the process design problem is re-defined as to produce biodiesel and fatty alcohol at a purity of $99.5 \mathrm{wt} \%$. In this option, glycerol is used as a fuel to produce hydrogen through a reforming process and the obtained hydrogen is used in the fatty alcohol production. The performance criterion is to maximize the net present value (NPV) of the process, defined as: Objective function

$\operatorname{Max} \mathrm{NPV}=f(X, Y)$

$$
\begin{aligned}
\mathrm{NPV} & =\left[\left(F_{\text {bio }} P_{\text {bio }}+F_{\text {fat }} P_{\text {fat }}\right)(P / A(i, n))-\left(F_{\text {oil }} P_{\text {oil }}+F_{\text {met }} P_{\text {met }}\right.\right. \\
& +F_{\text {cat }} P_{\text {cat }}(P / A(i, n))-\left(Q_{\text {reactor }} P_{\text {steam }}+Q_{r, i} P_{\text {stam }}+Q_{C, i} P_{\text {steam }}\right. \\
& \left.\left.+Q_{\text {elec }} P_{\text {elec }}\right)(P / A(i, n))-D(P / A(i, n))-\Sigma Y_{i} C(X, a)\right]
\end{aligned}
$$


Table 8

Screening alternatives for biodiesel production integrated with fatty alcohol production.

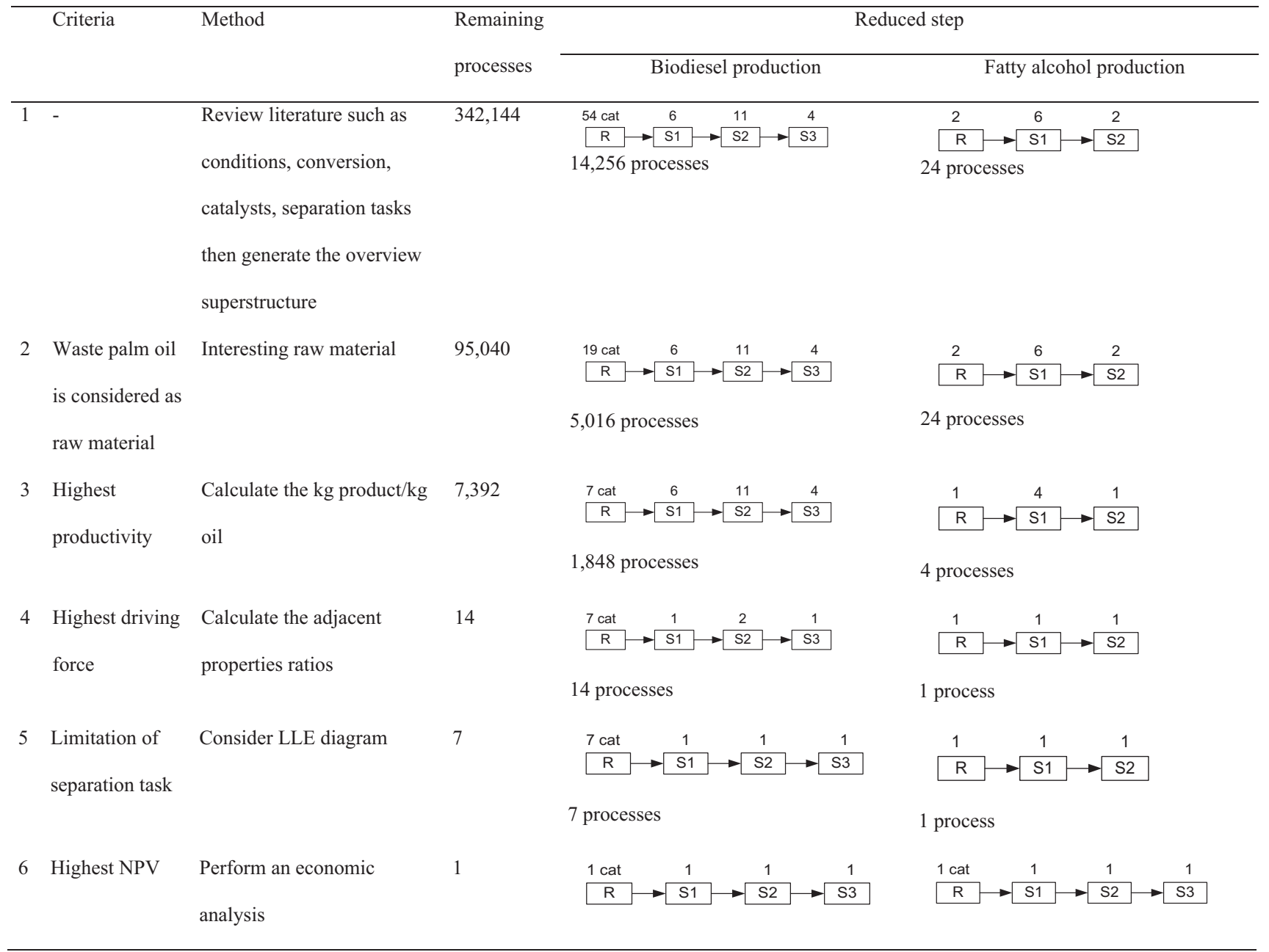

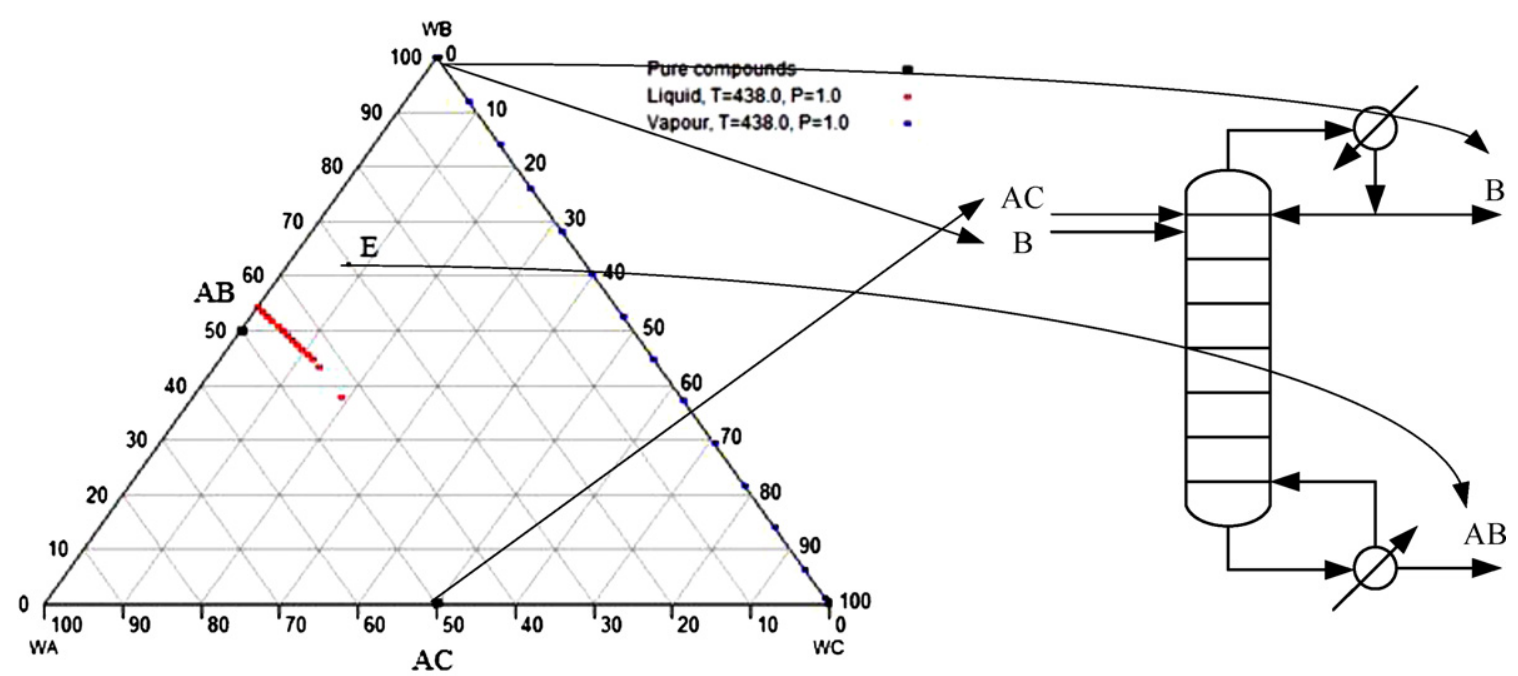

Fig. 13. Ternary phase diagram for three elements. 


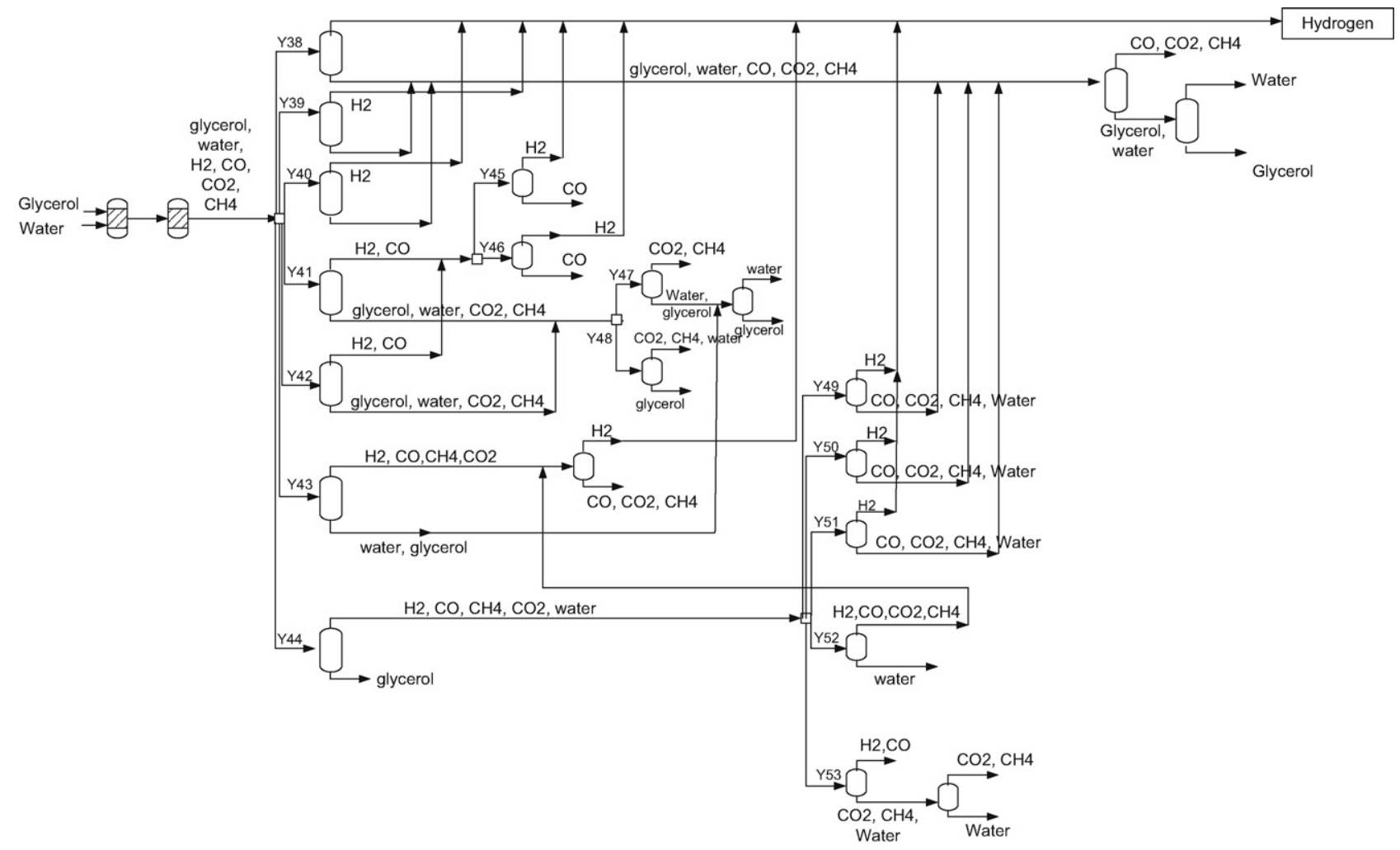

Fig. 14. The superstructure for hydrogen production.

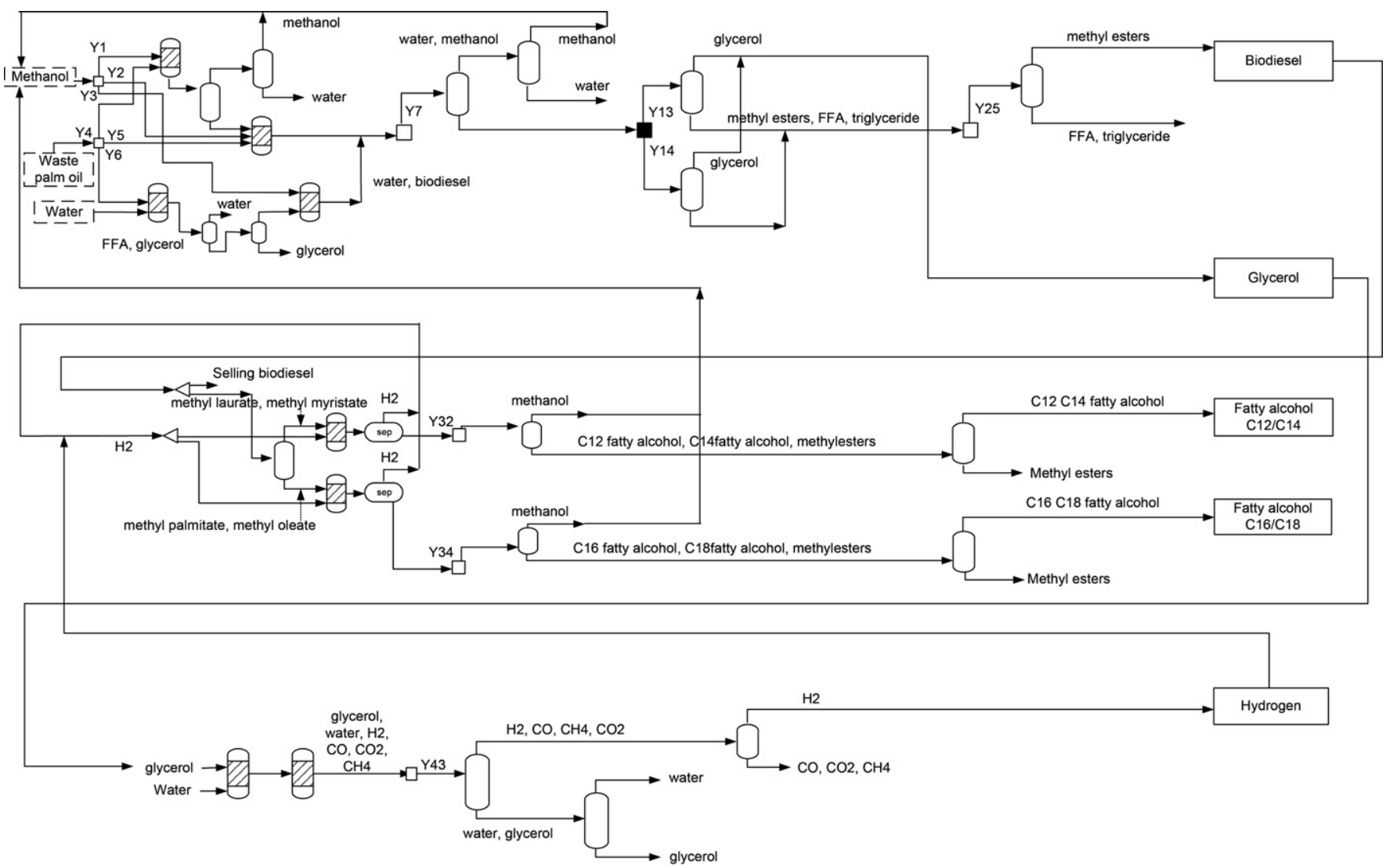

Fig. 15. The flowsheet of alternative processes for biodiesel production integrated with hydrogen and fatty alcohol productions

Please cite this article in press as: Simasatitkul, L., et al. Design methodology for bio-based processing: Biodiesel and fatty alcohol production. Computers and Chemical Engineering (2013), http://dx.doi.org/10.1016/j.compchemeng.2013.01.018 
Table 9

Comparison of design with and without process intensification for heterogeneous acid catalyzed process for biodiesel production (not including fatty alcohol production).

\begin{tabular}{llc}
\hline Parameters & $\begin{array}{l}\text { Process with } \\
\text { intensification }\end{array}$ & $\begin{array}{l}\text { Process without } \\
\text { intensification }\end{array}$ \\
\hline Amount of biodiesel $(\mathrm{kmol} / \mathrm{h})$ & 153.1 & 137.6 \\
Heating duty $(\mathrm{kJ} / \mathrm{h})$ & $7.798 \times 10^{7}$ & $9.307 \times 10^{7}$ \\
Cooling duty $(\mathrm{kJ} / \mathrm{h})$ & $6.87 \times 10^{7}$ & $7.806 \times 10^{7}$ \\
\hline
\end{tabular}

subject to

$h_{1}(X)=0$

$h_{2}(X)=0$

$g_{1}(X) \geq p_{1}$

$g_{2}(X) \geq p_{2}$

$p_{1}=99.5 \mathrm{wt} \%$

$p_{2}=99$ wt $\%$

$\sum_{i=N 1_{k}}^{N 2_{k}} Y_{i k}=1, \quad k=1, \quad \mathrm{NS}$
When the methodology is implemented step by step to design the process, it is found the superstructure of the process is similar to the previous one except that the hydrogen production process from glycerol is included (Fig. 14). The number of process alternatives for this option is $1.8 \times 10^{8}$. For the screening step by using the highest productivity and the easiest separation as criteria, the number of alternatives is reduced to 42 . The reduced superstructure is shown in Fig. 15. Unit operations for biodiesel and fatty alcohol productions are the same as the previous process design. For the hydrogen production process, flash separator is used to separate steam from other gaseous components in the first separation task while in the second separation task, membrane is employed to purify hydrogen. The remaining process alternatives are further analyzed through the economic analysis. It is noted that the fraction of biodiesel to produce fatty alcohol is assumed to be 0.4 because of the availability of glycerol to produce hydrogen. The results show that the alkali catalyzed process for biodiesel production integrated with hydrogen and fatty alcohol productions is the best economical process. The results of the screening procedure are shown in Table 10. It is noted that the NPV of the biodiesel process integrated with hydrogen and fatty alcohol processes $\left(6.33 \times 10^{8} \$ /\right.$ year $)$ is lower than that of the biodiesel process with fatty alcohol production $\left(7.88 \times 10^{8} \$\right.$ /year $)$. This indicates that the use of glycerol for hydrogen production is uneconomical

Table 10

Screening alternatives for biodiesel production integrated with hydrogen and fatty alcohol productions.

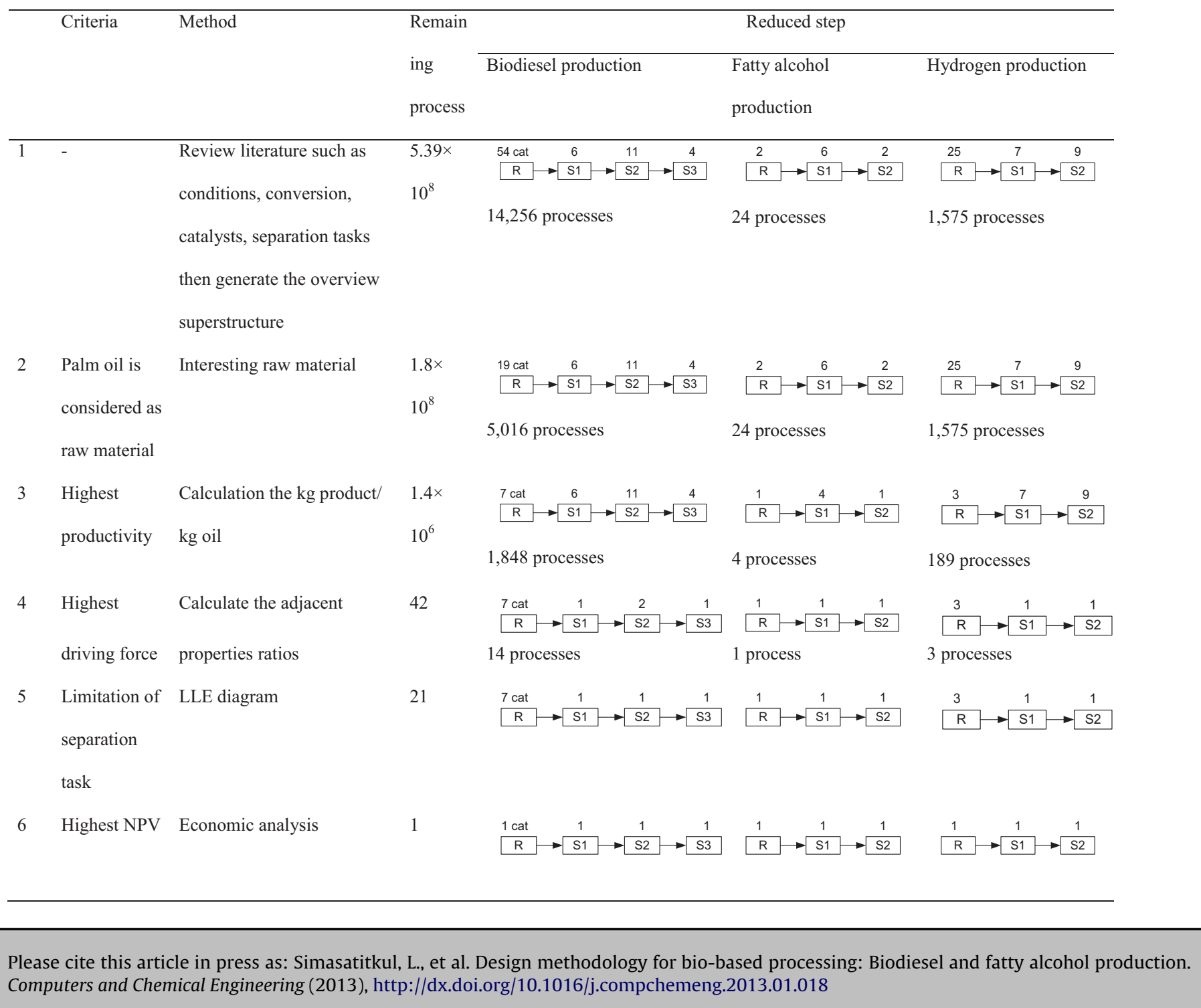


for the design conditions considered. A more detailed study is necessary, however, to establish the conditions under which this may become economically feasible.

\section{Conclusions}

The systematic design of processes for multiple main products plus side products has been presented and applied for biodiesel production integrated with fatty alcohol production. Although the methodology has been highlighted in this work for two main products, it is generic in principle. By increasing the number of renewable sources and main products, the model for an optimal biorefinery can be obtained. The mathematically complex problem has been managed by decomposing it into different hierarchical levels. According to the methodology, a heterogeneous acid catalyzed process for biodiesel production integrated with fatty alcohol production is better than other process alternatives. Process intensification improves the process by reducing heat duties and production costs. When glycerol obtained from biodiesel production is employed to produce hydrogen for use in fatty alcohol production, an alkali catalyzed process for biodiesel production integrated with hydrogen and fatty alcohol productions is the best process alternatives. The results also point out that the use of glycerol for hydrogen production is uneconomical. Note also that if the biodiesel and fatty alcohol process is located as part of a chemical process network where excess hydrogen is likely to be available, then the optimal process will become even more profitable.

\section{Acknowledgments}

Support from the Thailand Research Fund (RGJ-PhD Program), CAPEC of Technical University of Denmark (DTU) and the Computational Process Engineering Research Group, the Special Task Force for Activating Research (STAR), Chulalongkorn University Centenary Academic Development Project is gratefully acknowledged.

\section{Appendix A. Supplementary data}

Supplementary data associated with this article can be found, in the online version, at http://dx.doi.org/10.1016/j.compchemeng. 2013.01.018.

\section{References}

Alqahtani, A., Hellgardt, K., Holdich, R., \& Cumming, I. (2007). Integrated knowledge based system for process synthesis. Computer and Chemical Engineering, 24, 437-442.

d' Anterroches, L., \& Gani, R. (2005). Group contribution based process flowsheet synthesis, design and modelling. Fluid Phase Equilibria, 228-229, 141-146.

Bek-Pedersen, E., \& Gani, R. (2004). Design and synthesis of distillation system using a driving force approach. Chemical Engineering and Processing, 43, 251-262.

Bhatia, S., Mohamed, A. R., Ahmad, A. L., \& Chin, S. Y. (2007). Production of isopropyl palmitate in a catalytic distillation column: Comparison between experimental and simulation studies. Computer and Chemical Engineering, 31, 1187-1198.

Bokade, V. V., \& Yadav, G. D. (2009). Transesterification of edible and nonedible vegetable oils with alcohols over heteropolyacids supported on acid-treated clay. Industrial and Engineering Chemistry Research, 48, 9408-9415.
Chang, A., \& Liu, Y. A. (2010). Integrated process modeling and product design of biodiesel manufacturing. Industrial and Engineering Chemistry Research, 49, 1197-1213.

Diaz-Tovar, C., Mustaffa, A. A., Hukkerikar, A., Quaglia, A., Sin, G., Kontogeorgis, G., et al. (2011). Lipid processing technology: Building a multilevel modeling network. Computer Aided Chemical Engineering, 29, 256-260.

Douglas, J. (1988). Conceptual design of chemical processes. New York: McGraw Hill.

Dupont, R., \& Simonet, G. (1991). Process for manufacturing fatty alcohols. U.S. Patent 5001284.

Fleckenstein, T., Pohl, J., \& Carduck, F. J. (1991). Process for the hydrogenation of fatty acid methyl ester mixtures, U.S. Patent 5043485.

Georgiadis, M. C., Schenk, M., Gani, R., \& Pistikopoulos, E. N. (2002). The interactions of design. Control and operability in reactive distillation systems. Computers and Chemical Engineering, 26, 735-746.

Hostrup, M., Gani, R., Kravanja, Z., Sorsak, A., \& Grossmann, I. (2001). Integration of thermodynamic insights and MINLP optimization for the synthesis, design and analysis of process flowsheets. Computers and Chemical Engineering, 25, 73-83.

Hostrup, M., Harper, P. M., \& Gani, R. (1999). Design of environmentally benign processes: Integration of solvent design and process synthesis. Computers and Chemical Engineering, 23, 1395-1414.

Jaksland, C., Gani, R., \& Lien, K. (1995). Separation process design and synthesis based on thermodynamic insights. Chemical Engineering Science, 50, 511-530.

Jegannathan, K., Seng, C., \& Ravindra, P. (2011). Economic assessment of biodiesel production: Comparison of alkali and biocatalyst processes. Renewable and Sustainable Energy Reviews, 15, 745-751.

Kirkwood, R. L., Locke, M. H., \& Douglas, J. M. (1988). A proptotype expert system for synthesizing chemical process flowsheets. Computers and Chemical Engineering, $12,329-343$.

Lam, M. K., Lee, K. T., \& Mohamed, A. R. (2010). Homogeneous, heterogeneous and enzymatic catalysis for transesterification of high free fatty acid oil (waste cooking oil) to biodiesel: A review. Biotechnology Advances, 28, 500-518.

Lee, H., Lee, Y., Chien, I., \& Huang, H. (2010). Design and control of a heat-integrated reactive distillation system for the hydrolysis of methyl acetate. Industrial and Engineering Chemistry Research, 49, 7398-7411.

Lutze, P., Román-Martinez, A., Woodley, J. M., \& Gani, R. (2012). A systematic synthesis and design methodology to achieve process intensification in (bio) chemical processes. Computers and Chemical Engineering, 36, 189-207.

Ma, F., \& Hanna, M. A. (1999). Biodiesel production: A review. Bioresource Technology, $70,1-15$.

Mali, S. V., \& Jana, A. K. (2009). A partially heat integrated reactive distillation: Feasibility and analysis. Separation and Purification Technology, 70, 136.

Mitrofanov, I., Sansonetti, S., Abildskov, J., Sin, G., \& Gani, R. (2012). The solvent selection framework: Solvents for organic synthesis, separation processes and ionic liquids solvents. Computer Aided Chemical Engineering, 30, 762-766.

Narváez, P. C., Rincón, S. M., \& Sánchez, F. J. (2007). Kinetics of palm oil methanolysis. Journal of American Oil Chemists' Society, 84, 971-977.

Noiroj, K., Intarapong, P., Luengnaruemitchai, A., \& Jai-In, S. (2009). Comparative study of $\mathrm{KOH} / \mathrm{Al}_{2} \mathrm{O}_{3}$ and $\mathrm{KOH} / \mathrm{NaY}$ catalysts for biodiesel production via transesterification from palm oil. Renewable Energy, 34, 1145-1150.

Seider, W. D., Seader, J. D., \& Lewin, D. R. (2004). Product and process design principles. New York: Wiley.

Serri, N. A., Kamarudin, A. H., \& Abdul Rahaman, S. N. (2008). Preliminary studies for production of fatty acids from hydrolysis of cooking palm oil using C. rugosa lipase. Journal of Physical Science, 19, 79-88.

Silva, L. Y., Falleiro, R. M., Meirelles, A., \& Krahenbuhl. (2011). Vapor-liquid equilibrium of fatty acid ethyl esters determined using DSC. Thermochimica Acta, 512 $178-182$.

Skouras, S., Kiva, V., \& Skogestad, S. (2005). Feasible separations and entrainer selection rules for heteroazeotropic batch distillation. Chemical Engineering Science, $60,2895-2909$

Smith, R. (2005). Chemical process design and integration (1st ed.). New York: Wiley.

Song, E., Lim, J., Lee, H., \& Lee, Y. (2008). Transesterification of RBD palm oil using supercritical methanol. Supercritical Fluids, 44, 356-363.

Taylor, R., \& Krishna. (2000). Modelling reactive distillation. Chemical Engineering Science, 55, 5183-5229.

Turton, R., Bailie, R., Whiting, W., \& Shaeiwiz, J. (2009). Analysis, synthesis and design of chemical processes ( $3^{\text {rd }}$ ed.). Printice Hall.

Wang, Y., Ou, S., Liu, P., Xue, F., \& Tang, S. (2006). Comparison of two different processes to synthesize biodiesel by waste cooking oil. Journal of Molecular Catalysis A: Chemical, 252, 107-112.

Zhang, Y., Dube, M. A., McLean, D. D., \& Kates, M. (2003). Biodiesel production from waste cooking oil: 1 . Process design and technology assessment. Bioresource Technology, 89, 1-16. 